\title{
Metaphorical Thinking: Its Link to Neurochemistry of Learning
}

\author{
Cittoor Girija Navaneedhan, T. J. Kamalanabhan \\ Indian Institute of Technology, Madras, Chennai, India \\ Email: girija.navaneedhan@gmail.com
}

Received 30 December 2015; accepted 12 March 2016; published 15 March 2016

Copyright (C) 2016 by authors and Scientific Research Publishing Inc.

This work is licensed under the Creative Commons Attribution International License (CC BY).

http://creativecommons.org/licenses/by/4.0/

(c) (i) Open Access

\begin{abstract}
Metaphorical thinking has a close relationship to individual's learning capabilities as it determines an individual's ability to associate the given concept to an experience outside its environment for e.g. if a teacher explains the concept of Radioactivity in the class, Metaphorical thinking determines is the ability of the individual to associate the concept Radioactivity to solid waste decay which are totally different concepts yet possess a certain degree of similarity. For every association that Metaphorical thinking initiates, there exist neuronal activities in prefrontal cortex of the brain, the centre of learning. Greater is the ability of an individual to associate the experience with cognition, greater would be the ability to process the given information processing ability. The lack of ability to associate between experience and cognition results in attention deficiency among learners. The present paper explains that practice of Metaphorical thinking statements during teaching-learning process increases the brain activity in the prefrontal cortex of the brain in turn enables to promote the information processing ability of the individuals.
\end{abstract}

\section{Keywords}

Metaphorical Thinking, Learning Capabilities, Radioactivity, Information Processing Ability and Cognition

\section{Introduction}

Metaphorical thinking helps in promoting the association between familiar life experience with perceivable information put forward to develop concrete learning, Michaels and Carello (1981). Therefore, application of metaphorical thinking as a leaning tool promotes individual's learning ability. The word "learning" has several well defined meaning as understood by several Psychologists, for example Argyris and Schon understood learning as a new knowledge acquired by an individual which would reflect in his/her behaviour occurring repeatedly. 
Piaget explained learning as adaptation of individual's mental concept with experience and assimilating it. Kolbe proposed learning as transformation of knowledge to experience meaning acquiring knowledge and applying the knowledge to practice. According to Lewin, learning is a cyclic process in which an individual experiences a concrete observation as well as reflecting on it to form a abstract concept, making generalizations to create new ideas and applying it to a new situation to experience another concrete observation in a continuous manner. Therefore, from above definitions one could understand learning involves some novel experience an individual perceives as the result of stimulation occurring in the brain (Gurian \& Stevens, 2005). Hence, conscious practice of Metaphorical thinking in teaching learning process helps in triggering neuronal activity in the prefrontal cortex of the brain, the centre of learning (Lakoff \& Johnson, 1980). Research work carried out in the field of Neuro Science education revealed that frontal lobes of the cerebrum including the prefrontal cortex continue to develop till early adulthood increasing the ability to plan, reasoning out etc. (James, 2007). The ability to reason out is linked to the ability of brain to think, to understand, to experience, to associate, to compare and contrast similar to the strengthening of muscles of a physical body by doing regular exercise (Lakoff \& Johnson, 1980). Metaphorical thinking initiates the ability of the brain to associate in order to response to the stimulus being the information put forward to the learners by initiating the synthesis of neurotransmitter "nor-epinephrine responsible for chemical synapses to occur (McKinnon, 2012). Chemical synapses promote neuron-neuron communication in response to the stimulus. The entire mechanism explaining the link between Metaphorical thinking and neurochemistry of learning is shown in the form a teaching learning model (Figure 1).

\section{Promotion of Metaphorical Thinking on Given Information through Association}

Research studies carried out in earlier times showed evidence that Metaphorical thinking has an impact on the part of the brain responsible for initiating logical reasoning. Therefore, it promotes problem solving ability among learners as it stimulates imagination; generate ideas, concepts and the ability to think outside the box. (Shinjo \& Myers, 1987; Inhoff et al., 1984; McCabe, 1983), pointed out that Metaphorical thinking influences individual's interpretation and communication skills. When the given information is explained by the teacher by implementing Metaphorical thinking through associations it helps to build cognitive structures during teachinglearning process, thus bringing harmony in the left and the right hemispheres of the brain represented as a simple model as shown below (Figure 2).

\section{Metaphorical Thinking and Neurotransmitters}

Whenever given information is received as a stimulus promoted through metaphorical thinking through associations it initiates neuron-neuron communication through synapses synthesizing the neuro transmitter nor-epinephrine. Therefore, it is understood that more the teacher promotes metaphorical thinking through associations more would be the frequency of chemical synapses triggering in the synthesis of neurotransmitter nor-epinephrine in prefrontal region a centre for thinking skills of the brain. One of the functions of nor-epinephrine is to promote learning. Therefore, it could be suggested that the promotion of the given information through metaphorical thinking statements involving associations stimulates the prefrontal region of the brain initiating the neuron-neuron firing through chemical synapses facilitating through the neurotransmitter nor-epinephrine. The

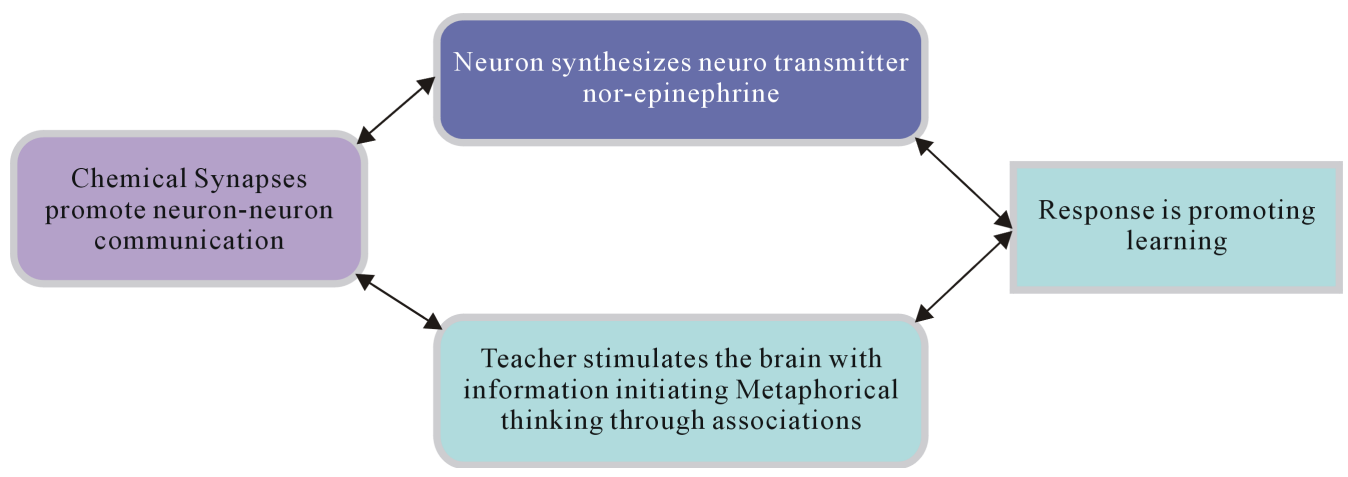

Figure 1. Teaching-learning model showing the link between metaphorical thinking and neurochemistry of learning. 
overall mechanism of neurochemistry of learning could be explained in the following sequential order (Figure 3).

\section{Objectives of the Study}

- To propose a simple mechanism showing the influence of metaphorical thinking on neuro-Chemistry of learning.

- To evaluate the cognitive ability of teachers based on delivery of content, activity and assessment.

- To find the impact of content, activity and assessment on academic performance of Science.

- To find out the impact of metaphorical thinking on cognitive structures in turn reflecting on academic performance.

\section{Research Questions}

- Is there a relationship between metaphorical thinking on cognitive structures?

- How metaphorical thinking through associations promote learning?

- How the ability of teachers delivering the content, activity and assessment influence the academic performance of learners?

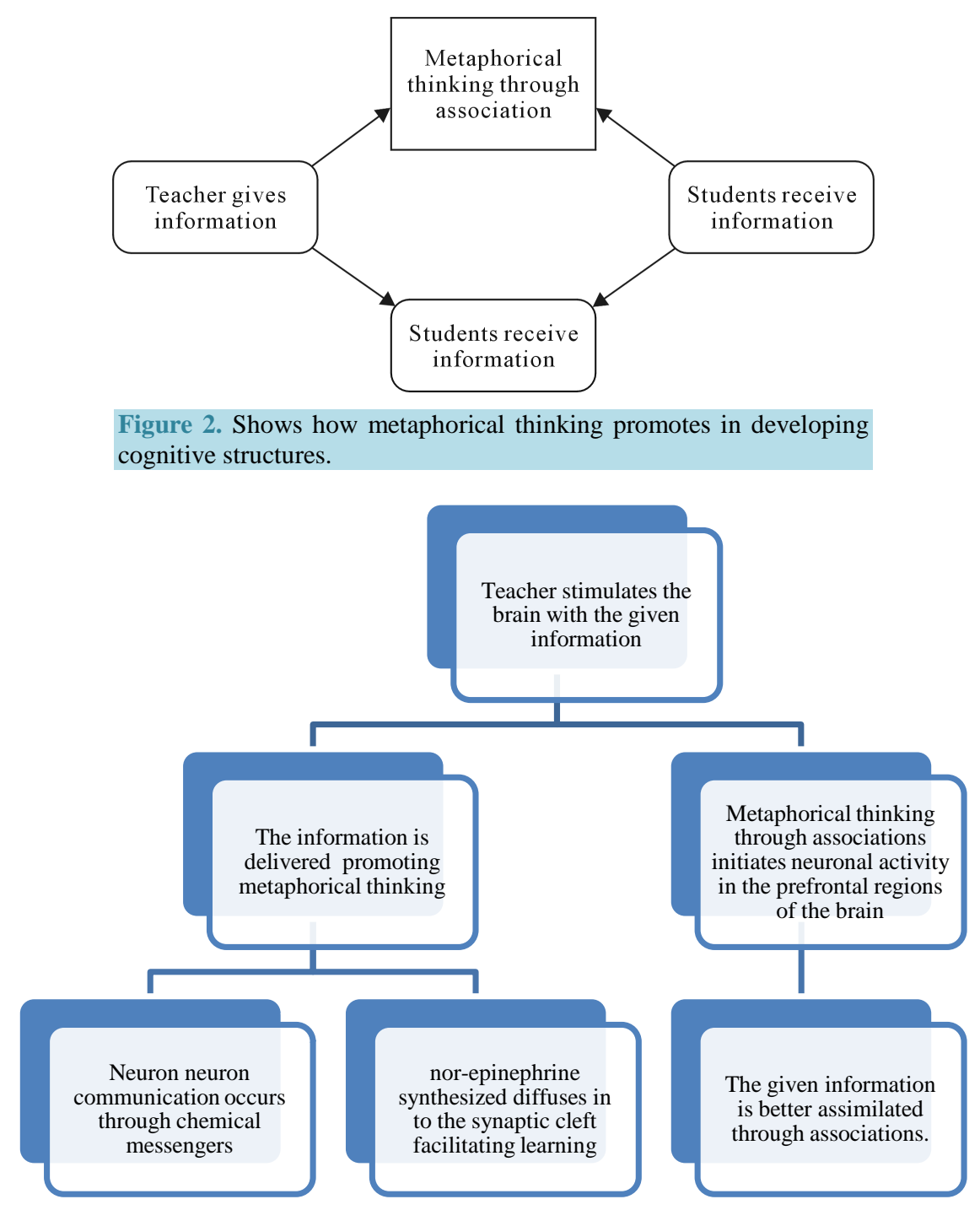

Figure 3. Shows the mechanism of neurochemistry of learning. 


\section{Design of the Study}

The experiment involved teacher sample handling IX grade following C.B.S.E (Central Board of Secondary Education, India) curriculum. A sample consisting of 25 male and 75 female teachers in the age group 30 to 50 years were randomly selected for the study. The investigator prepared the lesson plan for IX grade Science class incorporating metaphorical thinking statements through associations. This lesson plan template was used in Science class and the teachers who handle the subject in a regular manner are educated about the Metaphorical thinking technique, its practice and educational implications in teaching-learning process. Teachers are encouraged by the investigator to use statements which would induce Metaphorical thinking relevant to the content that the teacher teaches in the class. This is done by asking the teachers to observe the class of the investigator. The investigator interacts with the teachers, asking them how they plan the lesson for a particular period, modifying their lesson plan by incorporating statements which initiate metaphorical thinking without disturbing their routine slowly inculcating the habit of using statements which would initiate Metaphorical thinking . The following model shows how the investigator planned the design of the study (Figure 4).

The procedure of teachers observing the class of the investigator is carried out for a period of six weeks. At the end of six week duration the investigator conducted the survey among the teacher sample by distributing the questionnaire evaluating the cognitive structures as well as collecting pre and post academic performance of students in the subject concerned. The scores thus obtained are evaluated for its relationship with academic performance.

\section{Research Tool}

Cognitive structure questionnaire was designed by the investigator based on the dimensions a) content b) activity and c) assessment. The questionnaire consists of 45 statements evaluates each of these dimensions. Each statement is evaluated on five point likert scale such as not important (1), somewhat important (2), Important (3), Very important (4), extremely important (5). The negative statements are scored in the reverse order. A pilot study was conducted to find the reliability and the validity of the questionnaire. The reliability is calculated by half split method and was found to be 0.689 and the validity was found to be square of the reliability was found to be 0.475 . The scores obtained by the survey method were subjected to descriptive statistical analysis using Microsoft Office 365 software. The results of the experiment are tabulated as follows (Figure 5).

\section{Results of the Study}

Relationship is shown between content, activity, and assessment with academic performance for pre and post tests.

From Table 1 and the graph it could be interpreted that the implementation of metaphorical thinking through associations has an impact on cognitive structure as well as the academic performance of the learners. In this experiment statistical study is limited to finding the " $r$ " values for pre and post academic performance with content, activity and assessment dimensions of the cognitive structure. The post test values were found to be significant for both male and female teachers as well as the entire sample.

\section{Discussion}

The significant positive correlation coefficient values "r" for post test of academic performance and cognitive

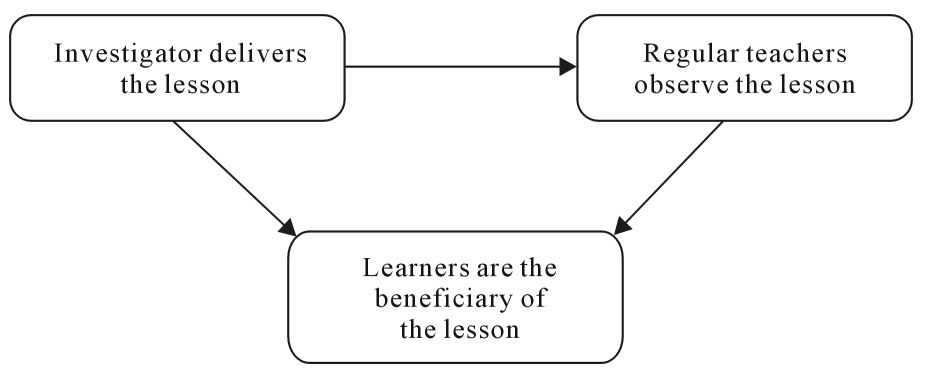

Figure 4. Shows the design of the experiment. 


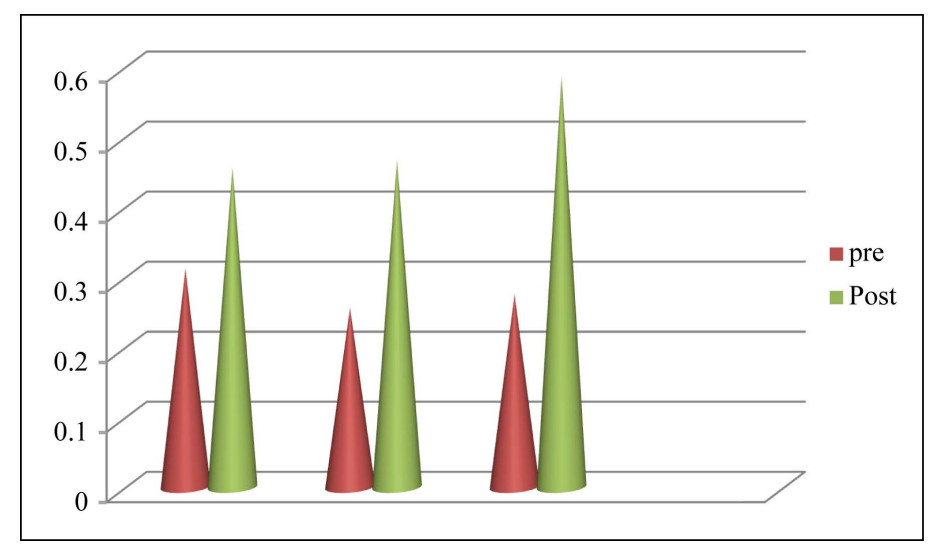

Figure 5. To show graphically the relationship between cognitive structure and academic performance.

Table 1. To show the correlation-coefficient " $r$ " values between the dimensions of cognitive structures and the pre and post academic performance.

\begin{tabular}{|c|c|c|c|c|c|c|c|}
\hline \multirow{2}{*}{ S. No } & \multirow{2}{*}{$\mathrm{N}$} & \multicolumn{2}{|c|}{$\begin{array}{l}\text { "r" for content and academic } \\
\text { performance }\end{array}$} & \multicolumn{2}{|c|}{$\begin{array}{c}\text { " } \mathrm{r} \text { ” for activity and academic } \\
\text { performance }\end{array}$} & \multicolumn{2}{|c|}{$\begin{array}{c}\text { "r" for assessment and academic } \\
\text { performance }\end{array}$} \\
\hline & & Pre & Post & Pre & Post & Pre & Post \\
\hline 1 & 100 & 0.312 N.S & $0.456^{* *}$ & 0.256 N.S & $0.524^{* *}$ & 0.345 N.S & $0.643^{* *}$ \\
\hline 2 & 25 (Males) & 0.256 N.S & $0.467^{* *}$ & 0.325 N.S & $0.634^{* *}$ & 0.278 N.S & $0.569^{* *}$ \\
\hline 3 & 75 (Females) & 0.275 N.S & $0.587^{* *}$ & 0.378 N.S & $0.689^{* *}$ & 0.298 N.S & $0.756^{* *}$ \\
\hline
\end{tabular}

${ }^{*} p<0.05,{ }^{* *} p<0.01,{ }^{* * *} p<0.001$, N.S $=$ Not Significant.

structure shows that practice of metaphorical thinking in teaching-learning process enables the learners to develop a sense of the given information that is the application and the synthesis level of the information. Association for supervision and curriculum development has mentioned a few case studies in which the teachers practicing teaching-learning methodology involving statements that make creative comparison (metaphorical thinking), explaining cause-effect relation, quoting observations and experiences proved to be effective improving the grades of the learners. A regular practice of metaphorical thinking statements during teaching-learning process develops independent thinking among learners. Osborne and Brady (2000) in their study reported the case study of a four year old child who could make a truck from Styrofoam egg carton, a moulded plastic tray, cardboard cylinders and glue by connecting them together to make sense of appearance of a truck .The child probably got the idea comparing it to a train . Promoting metaphorical thinking statements in the lesson plan enables to process new ideas as it is self directed and not governed by positive as well as negative reinforcement by the teacher where the distinction between brain and mind dissolves (Churchland, 2002). Many studies proved that implementing metaphorical thinking in teaching-learning process enables the teacher to present the knowledge through experiences facilitating teaching as an enjoyable task as it promotes the student's accountability as they develop their own meaning by their experiences in terms of casual, logical and interpersonal relationships (Habermas, 1990). The mechanism proposed in this paper explaining how metaphorical thinking is linked to Neuro-Chemistry of learning is shown by the research work carried out by Goleman (1995) which states that stimulus (that is the given information) by the teacher perceived by the sense organs eyes and ears travel first in the brain to the thalamus and then across a single synapse to the amygdala; a second signal from the thalamus is routed to the neocortex or the prefrontal lobe the thinking brain. In the present study correlation coefficient values found between the components of cognitive structure and the academic performance reveal the effectiveness with which the teacher delivers the given information integrating metaphorical thinking in the lesson plan. Several empirical research studies carried out in metaphorical thinking revealed that comparison-initiated transfer of structured knowledge plays a critical role in a broad array of cognitive tasks, such as solving math word problems (Read, 1987), forming legal arguments (Marchant et al., 1991), and predicting an individual's behavior 
(Read, 1987). In another study conducted by Hansen, Richland, \& Tomlison (2011), "Metaphor and creativity in learning Science” concluded that engaging students in metaphorical thinking enhances their creativity and conceptual understanding of Science content in depth being the major objective of teaching-learning Science.

\section{Conclusion}

Neuroscience studies on human cognition in recent years gave several insights to promote learning in a variety of means suggested by several researches in this field, an attempt made by the authors reveal that practice of metaphorical statements through associations is one of effective way to promote teaching learning of science. The authors argued that the teacher stimulating the senses of the learners could achieve desirable learning outcome by careful planning of the content, activities and assessment related to the content so that the learners engage themselves in creative thinking. The ability of learners to develop creative thinking pattern is reflected from the ability of teacher who frame the lesson plan incorporating metaphorical thinking statements through associations. As we all know that learning is a very complex phenomenon which involves several simultaneous processes occurring in the conscious as well as subconscious level of brain a simple model explaining the neuro-chemistry of learning gives an understanding how metaphorical thinking promotes learning?

\section{Limitations of the Study}

The present study has shown theoretically the relationship between Metaphorical thinking and the NeuroChemistry of learning, the experimental evidence establishing the activity in the prefrontal cortex is progressing slowly as there are several ethical issues involved.

\section{References}

Churchland, P. S. (2002). Brain-Wise: Studies in Neurophilosophy. Cambridge, MA: MIT Press.

Goleman, D. (1995). Emotional Intelligence. New York: Bantam Books.

Gurian, M., \& Stevens, K. (2005). The Minds of Boys: Saving Our Sons from Falling Behind in School and Life. San Francisco: Jossey-Bass.

Habermas, J. (1990). Moral Consciousness and Communicative Action. Trans Lenhardt, C., \& Weber Nicholson, S.; Cambridge, Mass: MIT Press.

Hansen, J., Baumer, E. P. S., Richland, L., \& Tomlinson, B. (2011) Metaphor and Creativity in Learning Science. 04/01/ 2010-03/31/2011, American Educational Researchers Association Annual Conference (AERA). (New Orleans, Louisiana).

Inhoff, A., Lima, S., \& Carroll, P. (1984). Contextual Effects on Metaphor Comprehension in Reading. Memory and Cognition, 12, 550-567. http://dx.doi.org/10.3758/BF03213344

James, A. N. (2007). Teaching the Male Brain: How Boys Think, Feel, and Learn in School. Corwin Press.

Lakoff, G., \& Johnson, M. (1980). Metaphors We Live by. Chicago: University of Chicago Press. http://dx.doi.org/10.7208/chicago/9780226470993.001.0001

Marchant, G., Robinson, J., Anderson, U., \& Schadewald, M. (1991). Analogical Transfer and Expertise in Legal Reasoning. Organizational Behavior and Human Decision Processes, 48, 272-290. http://dx.doi.org/10.1016/0749-5978(91)90015-L

McCabe, A. (1983). Conceptual Similarity and the Quality of Metaphor in Isolated Sentences versus Extended Context. Journal of Psycholinguistic Research, 12, 41-60. http://dx.doi.org/10.1007/BF01072713

McKinnon, A. M. (2012). Metaphors in and for the Sociology of Religion: Towards a Theory after Nietzsche. Journal of Contemporary Religion, 27, 203-216. http://dx.doi.org/10.1080/13537903.2012.675688

Michaels, C. F., \& Carello, C. (1981). Direct Perception. Englewoodcliffs, NJ: Printicehall.

Osborne, M. D., \& Brady, D. J. (2000). Joy and Pradox of Control. International Journal of Education and Arts, 1. http://ijea.asu.edu/index.html

Read, S. (1987). Similarity and Causality in the Use of Social Analogies. Journal of Experimental Social Psychology, 23, 189-207. http://dx.doi.org/10.1016/0022-1031(87)90031-X

Shinjo, M., \& Myers, J. (1987). The Role of Context in Metaphor Comprehension. Journal of Memory and Language, 26, 226-241. http://dx.doi.org/10.1016/0749-596X(87)90125-2 